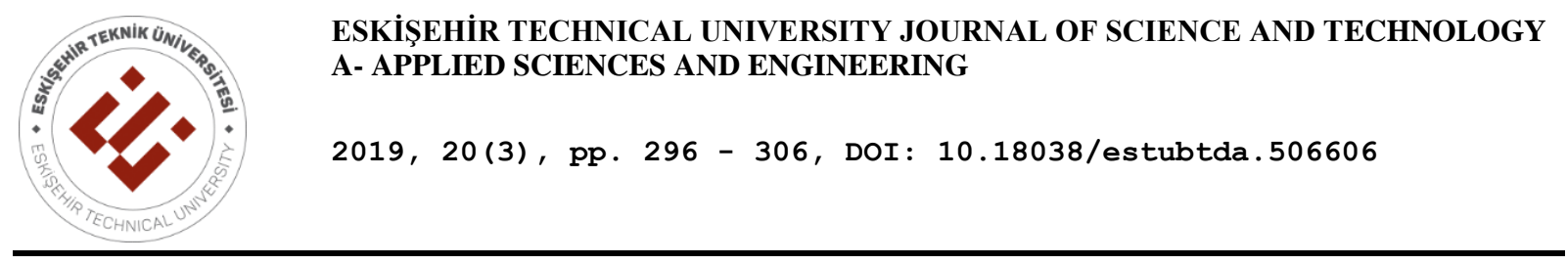

\title{
FABRICATION of n-ZnO:Mn/p-Si HETEROJUNCTION DIODES and ITS I-V, C-V CHARACTERISTICS
}

\author{
Seval AKSOY* \\ Department of Physics, Faculty of Arts and Sciences, University of Sinop, Sinop, Turkey
}

\begin{abstract}
To investigate the effects of $\mathrm{Mn}$ dopant on $\mathrm{n}-\mathrm{ZnO} / \mathrm{p}$-Si device performance, $\mathrm{ZnO}$ films were produced in different $\mathrm{Mn}$ dopant by the sol gel spin coating method. Morphological properties of the films were studied by FESEM. Then, the n- $\mathrm{ZnO}: \mathrm{Mn} / \mathrm{p}-\mathrm{Si}$ heterojunction diodes were fabricated. The diode parameters were determined by $I-V$ measurements. The $n$ values of the diodes were found to be 8.38, 6.84 and 3.87, respectively, for the diodes produced using undoped, $1 \% \mathrm{Mn}$ doped and $3 \%$ Mn doped $\mathrm{ZnO}$ films. At the same time, electrical parameters were determined to compare by using Cheung and Norde methods. According to the evaluation of $n$ values obtained by different methods, an improvement on the rectifying properties of the $\mathrm{ZnO}$ diode with Mn dopant has been observed. In the continuation of the study, the photovoltaic properties of the heterojunction diodes have been studied. The results obtained at different illumination intensities showed that the diodes are sensitive to light. $C$ - $V$ measurements of the fabricated diodes are also investigated in detail.
\end{abstract}

Keywords: Mn doped $\mathrm{ZnO}$, Sol gel, Heterojunction diode, FESEM, Electrical parameters

\section{INTRODUCTION}

Zinc oxide $(\mathrm{ZnO})$ is a semiconductor with a wide band gap and a large exciton binding energy $(3.37 \mathrm{eV}$, $60 \mathrm{meV}$ ). When the literature is examined, it has been found that many methods have been used to deposit undoped and $\mathrm{Mn}$ doped $\mathrm{ZnO}$ films. Some of these methods are hydrothermal synthesis [1], spray pyrolysis [2] and sol gel [3]. Among these methods, sol gel method has many advantages such as: ease of use, low cost, applicability at low temperatures, short processing times and easy coating of different substrates. Many researchers have studied the structural, morphological and electrical properties of transition metal (Fe, Ni, Mn, etc.) doped semiconductor materials [4-6]. $\mathrm{ZnO}$ is a suitable host material for $\mathrm{Mn}$ doped as it is appropriate to replace the $\mathrm{Zn}^{2+}$ cations of $\mathrm{Mn}^{2+}$ metal ions when considering the ionic diameters of $\mathrm{Mn}^{2+}$ and $\mathrm{Zn}^{2+}$. Researchers have done some experimental studies on $\mathrm{Mn}$-doped $\mathrm{ZnO}$ using physical and chemical methods [7-9]. These studies reported currently relate to the physical property of $\mathrm{Mn}$-doped $\mathrm{ZnO}$ films but there are very few studies on the $\mathrm{n}-\mathrm{ZnO}: \mathrm{Mn} / \mathrm{p}$-Si heterojunction [3], [10]. One of these studies in the literature was conducted by R.N. Gayen and R. Paul [3]. R.N. Gayen and R. Paul synthesized Mn doped $\mathrm{ZnO}$ films by using sol gel method. They investigated the structural, morphological and optical properties of films. The results of the microstructural and compositional analysis showed that the Mn dopant did not affect the hexagonal structure of $\mathrm{ZnO}$. They reported that the films had high transparent in the visible region. In their work, it was reported a decreasing in both the particle size and optical band values with increasing Mn dopant. They reported that the diode parameters changed with Mn dopant. Both ideality factor and barrier height decreased with Mn dopant. The authors reported that the Schottky diode became more ideal with increasing Mn dopant. In other study, İ. Taşçığlu et al. [10] deposited $\mathrm{Mn}$ doped $\mathrm{ZnO}$ films by the same method. The authors investigated the electrical properties of the diodes fabricated using these films and they reported that while the ideality factor value of diode decreased with Mn dopant, barrier height of diode increased. Also, using Norde method, they calculated barrier height values and series resistance values as $0.91 \mathrm{eV}$, $13.77 \mathrm{k} \Omega$ for $\mathrm{ZnO}$ : Mn/p-Si diode, $0.82 \mathrm{eV}, 5.18 \mathrm{k} \Omega$ for $\mathrm{ZnO} / \mathrm{p}$-Si diode, respectively.

*Corresponding Author: saksoy@sinop.edu.tr

Received: 02.01.2019 Published: 26.06.2019 
In this paper, undoped and $\mathrm{Mn}$ doped $\mathrm{ZnO}$ films were prepared by sol gel spin coating technique (SSCT) on $\mathrm{p}$-Si substrates. The prepared films were characterized by FESEM. The influence of $\mathrm{Mn}$ concentration on the electrical properties of obtained diodes has been investigated in detail. The values of $n, \phi_{b}$ and $R_{S}$ were calculated by different methods. In addition, in the scope of the electrical properties, capacitance-voltage $(C$ - $V)$ properties of the diodes have been also studied.

\section{EXPERIMENTAL DETAIL}

Undoped and $\mathrm{Mn}$ doped $\mathrm{ZnO}$ films were deposited by SSCT. Manganese (II) acetate tetrahydrate $\left(\mathrm{Mn}\left(\mathrm{CH}_{3} \mathrm{COO}\right)_{2} .4 \mathrm{H}_{2} \mathrm{O}, \mathrm{MnAc}, 99.9 \%\right.$, Acros) was used as a manganese cation precursor. MnAc was added as 1 and $3 \mathrm{wt} \%$ into the ZnAc solution. The concentration of these solutions was $0.05 \mathrm{M}$. The samples are named $\mathrm{ZnO}, \mathrm{ZM} 1$ and ZM3, respectively. Detailed information on the experimental procedure was included in our previous study [11, 12]. The surface morphology of the films was determined by using ZEISS Ultraplus model field emission scanning electron microscopy (FESEM). Aluminum ohmic contacts were made using PVD-HANDY/2S-TE (Vaksis Company, Turkey) vacuum thermal evaporation system. $I-V$ and $C$ - $V$ characteristics of the diodes were carried out using a KEITHLEY 4200 SCS/CVU and Signatone probe station at room temperature. For illumination, solar simulator (Asahi-HAL320) with 1.5AM filter was used.

\section{RESULTS and DISCUSSION}

\subsection{Morphological Properties}

FESEM was used to investigate the morphological properties of films. Figure 1 shows the FESEM images of the films under the different magnifications. FESEM images show that all films consist of spherical structures. The surface morphology of the films is similar to the with $\mathrm{Mn}$ doped $\mathrm{ZnO}$ films in the literature [13-15]. In addition, when the amount of Mn dopant increases, the particle size increases slightly and the aggregation of the particles on the surface are appeared. So, as a result of this aggregation, the bigger particles on the surface depending on increasing Mn dopant have been clearly seen in SEM images.

\subsection{Current-Voltage and Capacitance-Voltage Characteristics of the Heterojunction Diodes}

One of current transport mechanisms is thermionic emission (TE) theory. In addition to TE process, there are (direct) tunneling and thermally assisted tunneling process. These two processes should be important due to the temperature [16]. According to TE theory, carriers exceeding the barrier are only energized carriers larger than $\phi_{\mathrm{b}}$ and they contributed to the current. The concentration of this carrier significantly influences the transport processes in the heterostructures. The carrier concentration of $\mathrm{p}-\mathrm{Si}$ is higher than the carrier concentration of $\mathrm{ZnO}\left(\sim 10^{17} \mathrm{~cm}^{-3}\right.$ for $\mathrm{n}-\mathrm{ZnO}$ and $\sim 10^{19} \mathrm{~cm}^{-3}$ for $\mathrm{p}$-Si) [17, $18]$

The current-voltage $(I-V)$ characteristics of the heterojunction diodes measured at low bias voltage indicate that the characteristics exhibit an exponential behavior. Therefore, the $I-V$ characteristics of the heterojunction diodes can be analyzed by the following relationship [19] 


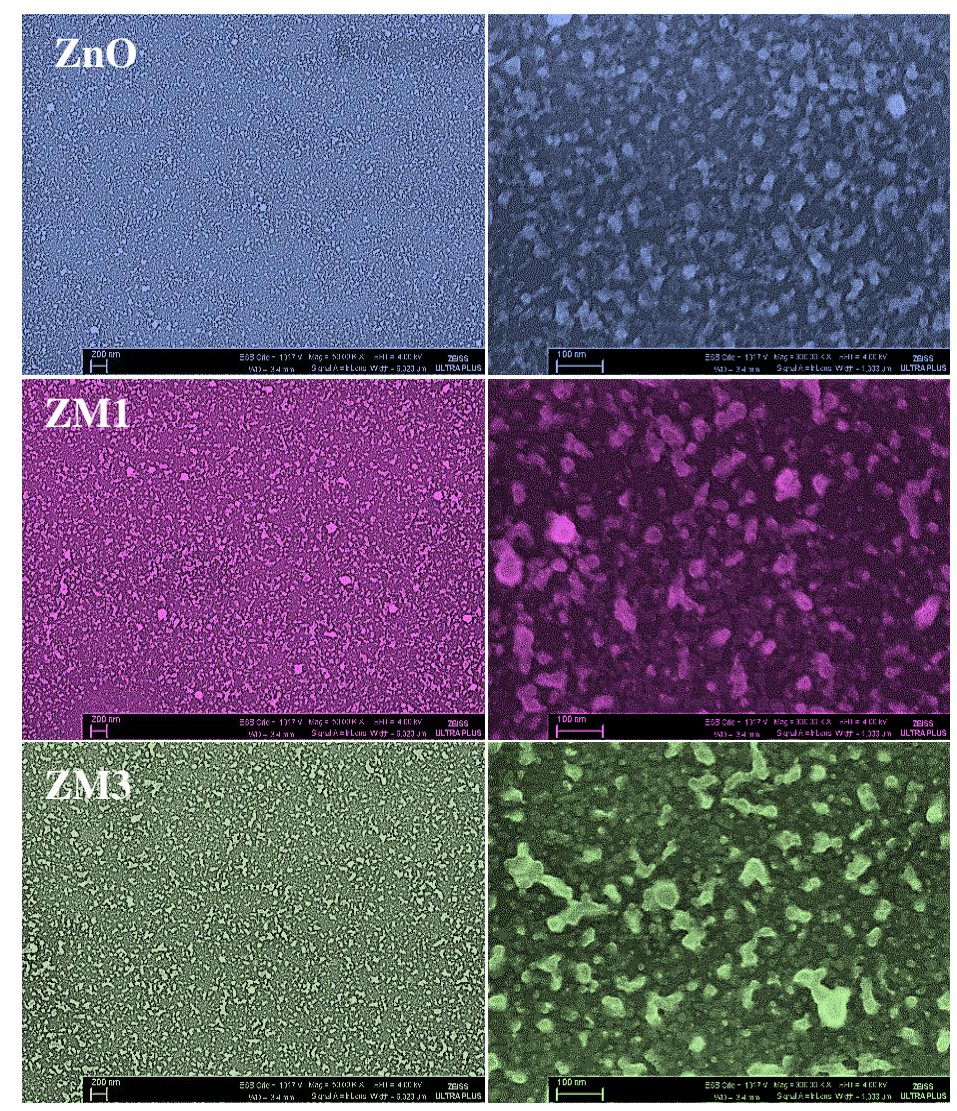

Figure 1. FESEM images of the ZM films.

$$
I=I_{S}\left[\exp \left(\frac{q\left(V-I R_{S}\right)}{n k T}\right)-1\right]
$$

where $q$ is the electronic charge, $V$ is the applied bias voltage, $n$ is the ideality factor, $k$ is the Boltzmann constant, $R_{S}$ is the series resistance and $T$ is the absolute temperature in Kelvin, $I_{S}$ is the reverse saturation current and given by,

$$
I_{s}=A A^{*} T^{2} \exp \left(-\frac{q \phi_{b}}{k T}\right)
$$

where $A$ is the rectifier contact area, $A^{*}$ is the effective Richardson constant $\left(32 \mathrm{~A} / \mathrm{cm}^{2} \mathrm{~K}^{2}\right.$ for p-Si and $\mathrm{n}-\mathrm{ZnO})$ and $\phi_{b}$ is the apparent barrier height at zero-bias. The slope of the linear region in the forward bias of the $I-V$ plot gives the n value, and Equation (1) can be written as follows:

$$
n=\frac{q}{k T}\left(\frac{d V}{d(\ln I)}\right)
$$

In addition, the barrier height can be obtained from Equation (2),

$$
\phi_{b}=\frac{k T}{q} \ln \left(\frac{A A^{*} T^{2}}{I_{0}}\right)
$$


The experimental values of $n$ and $\phi_{b}$ are given in Table 1 . The ideality factor values of the heterojunction diodes were calculated from Figure 2. The ideality factor of the heterojunction diodes approached to the ideal value with the increase amount of Mn dopant. Nevertheless, the ideality factor values of the heterojunction diodes are significantly greater than the expected value. It is thought that this difference is due to the surface states, the oxide layer on the surface of $\mathrm{p}-\mathrm{Si}$ or the series resistance effect. R.N. Gayen and R. Paul found similar results and reported that this was due to non-ideal junction formation. They reported the cause of the non-ideal junction as surface defects acting as a recombination center and series resistance [3].

Table 1. Heterojunction diode parameters of heterojunction diodes

\begin{tabular}{|c|c|c|c|c|c|c|c|c|c|}
\hline \multirow{2}{*}{ Sample } & \multirow{2}{*}{$\boldsymbol{I}_{\mathbf{0}}(\mathbf{A})$} & \multicolumn{2}{|c|}{$\boldsymbol{n}$} & \multicolumn{3}{c|}{$\boldsymbol{\phi}_{\boldsymbol{b}}(\mathbf{e V})$} & \multicolumn{3}{c|}{$\boldsymbol{R}_{\boldsymbol{s}}(\mathbf{k \Omega})$} \\
\cline { 3 - 11 } & & $\boldsymbol{I}-\boldsymbol{V}$ & $\boldsymbol{d} \boldsymbol{V} / \boldsymbol{d} \boldsymbol{I}$ & $\boldsymbol{I}-\boldsymbol{V}$ & $\boldsymbol{H}(\boldsymbol{I})$ & Norde & $\boldsymbol{d} \boldsymbol{V} / \boldsymbol{d} \boldsymbol{I}$ & $\boldsymbol{H}(\boldsymbol{I})$ & Norde \\
\hline $\mathbf{Z n O}$ & $8.35 \times 10^{-8}$ & 8.38 & 8.73 & 0.54 & 0.69 & 0.41 & 2.83 & 1.11 & 7.07 \\
\hline $\mathbf{Z M 1}$ & $3.55 \times 10^{-8}$ & 6.84 & 6.97 & 0.56 & 0.70 & 0.49 & 41.14 & 15.79 & 3.61 \\
\hline $\mathbf{Z M 3}$ & $6.25 \times 10^{-9}$ & 3.87 & 4.08 & 0.61 & 0.75 & 0.56 & 36.56 & 9.09 & 20.50 \\
\hline
\end{tabular}

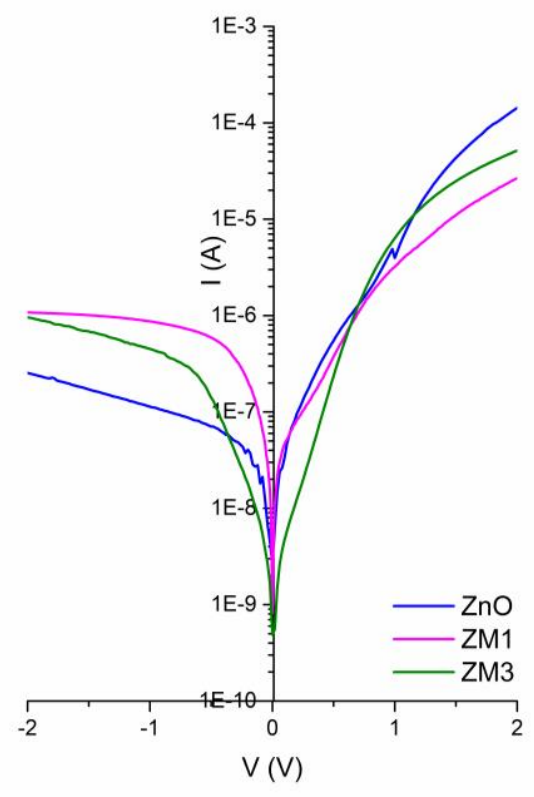

Figure 2. $I-V$ characteristics of heterojunction diodes

There are three interfaces, in the metal/n-ZnO:Mn/p-Si heterojunction, such as metal/p-Si, $\mathrm{p}-\mathrm{Si} / \mathrm{n}-\mathrm{ZnO}$ and $\mathrm{ZnO} /$ metal. Metal/p-Si and $\mathrm{ZnO} /$ metal are ohmic between these interfaces. A thin native $\mathrm{SiO}_{\mathrm{x}}$ layer is also present in the $\mathrm{n}-\mathrm{ZnO} / \mathrm{p}-\mathrm{Si}$ interface. However, in this study, $\mathrm{n}-\mathrm{ZnO} / \mathrm{p}-\mathrm{Si}$ heterojuction diode parameters are discussed without considering a thin native $\mathrm{SiO}_{\mathrm{x}}$ layer present in the $\mathrm{n}-\mathrm{ZnO} / \mathrm{p}-\mathrm{Si}$ interface. The ultra-thin $(\sim 1-2 \mathrm{~nm}) \mathrm{SiO}_{\mathrm{x}}$ barrier, which carriers can easily tunnel through the barrier, does not affect both forward and reverse direction current. Therefore, the diode parameters of the n$\mathrm{ZnO} / \mathrm{p}$-Si heterojunction are mostly unaffected by the presence of the $\mathrm{SiO}_{\mathrm{x}}$ interface layer. In this study, the effect of $\mathrm{p}-\mathrm{Si} / \mathrm{n}-\mathrm{ZnO}$ interface can be mentioned in this study [18].

The $\phi_{b}$ values of the heterojunction diodes were calculated from the $(I-V)$ characteristics by using Equation 4 and given in Table 1. $\phi_{b}$ values increase with increasing Mn dopant and they are close to 
the difference in the working function of $\mathrm{Si}(4.97 \mathrm{eV})$ and the working function of $\mathrm{ZnO}(4.25 \mathrm{eV})$ [20]. The increase in the barrier height value with the increase in the amount of Mn dopant is consistent with the studies in the literature $[3,10]$.

The Cheung method is defined by the following functions [21]:

$$
I=I_{s} \exp \left[\frac{q\left(V-I R_{S}\right)}{n k T}\right]
$$

where the $R_{S}$ is the series resistance of heterojunction diode. The value of $R_{S}, n$, and $\phi_{b}$ is determined by the following equation:

$$
\begin{gathered}
\frac{d V}{d(\ln I)}=I R_{S}+n\left(\frac{k T}{q}\right) \\
H(I)=V-n\left(\frac{k T}{q}\right) \ln \left(\frac{I}{A A^{*} T^{2}}\right)
\end{gathered}
$$

where,

$$
H(I)=I R_{S}+n \phi_{b}
$$

Figure 3 shows the $d V / d \ln (I)-I$ plots drawn using $I-V$ characteristics. The slope of the plot of $d V / d(\operatorname{InI})-I$ will give the $R_{s}$ value and the y-axis intercept of the plot of $d V / d(\operatorname{InI})-I$ will give the $(n k T / q)$ value. $R_{S}$ and $n$ values determined using Figure 3 are given in Table 1 . The $n$ values obtained from the $I-V$ plot and the $n$ values obtained by using Cheung's method are slightly different. This situation is thought to be caused by series resistance and interface states [22]. However, in both methods, the $n$ values were decreased with increasing Mn dopant.

The H(I)-I graph plotted according to Equation 8 is given in Figure 3. In these graphs, the slope value of the plot gives the value of $R_{s}$, while the intercept of the y-axis of the plot gives the value of $n \phi_{b} . R_{S}$ and $\phi_{b}$ values determined from the plots (Figure 3) are given in Table 1. The $\phi_{b}$ values calculated from the $H(I)-I$ plots have the same trend as the $\phi_{b}$ values calculated from the $I-V$ characteristics. In other words, $\phi_{b}$ values increase with Mn dopant in both methods.
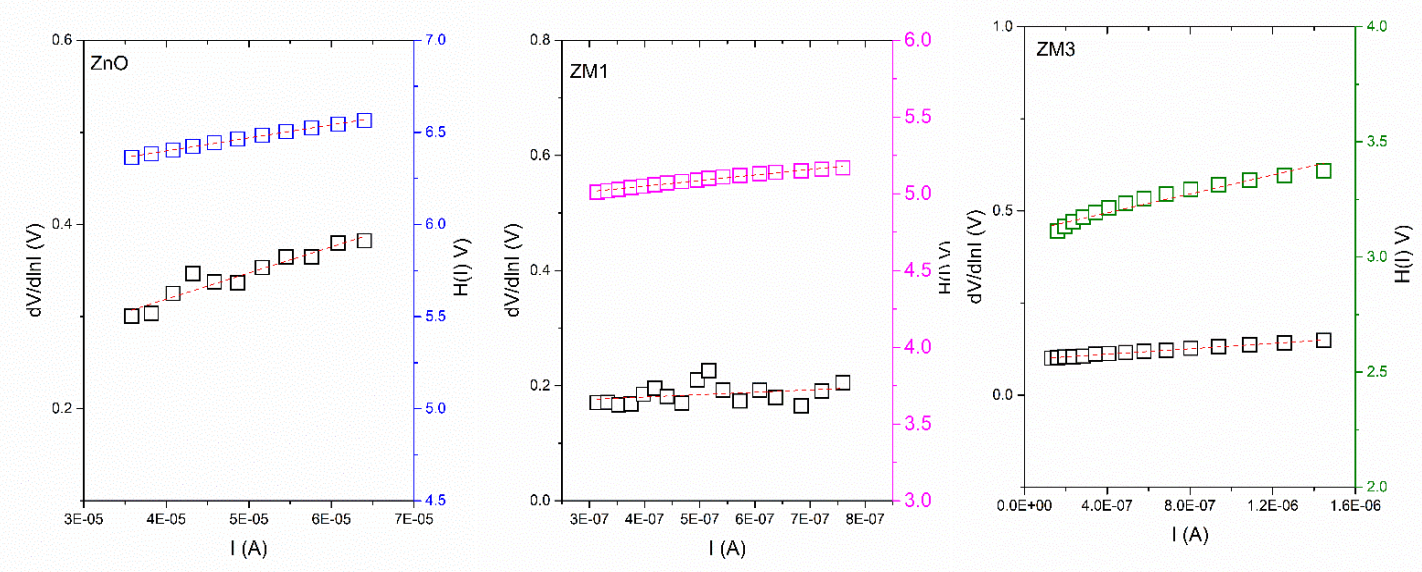

Figure 3. The forward bias bias $d V / d(\ln I)-I$ and $H(I)-I$ plots.

Another method for determining the barrier height and the series resistance value is the Norde method. The Norde method is given the following relation [23]: 


$$
F(V)=\frac{V_{0}}{\gamma}-\frac{k T}{q} \ln \left(\frac{I(V)}{A^{*} A T^{2}}\right)
$$

where $\gamma$ is a dimensionless and an integer greater than $n$. The $F(V)-V$ plots are shown in Figure 4. Using the following equations, the values of $\phi_{b}$ and $R_{S}$ are calculated:

$$
\begin{gathered}
\phi_{b}=F\left(V_{0}\right)+\frac{V_{0}}{\gamma}-\frac{k T}{q} \\
R_{S}=\frac{k T(\gamma-n)}{q I_{0}}
\end{gathered}
$$

where $F\left(V_{0}\right)$ is the minimum point of $F(V)$. Calculated $\phi_{b}$ and $R_{s}$ values are given in Table $1 . R_{S}$ values calculated from Cheung's method and Norde method were different. The reason of this difference may be the application of Cheung's model and the Norde model at different voltage ranges. That is, while Cheun's model is applied in the high voltage region, the Norde model is applied at full voltage range [23]. The values of $R_{S}$ determined in this study are quite high. This may be due to the interfacial layer and the resistance of the substrate. In addition, the low quality top contact of films can also increase the serial resistance value. In other words, in order to be able to produce the ideal device, the electrical contacts must be meticulously made. There is also a difference between $\phi_{b}$ values obtained from the Norde method and $I-V$ plot. This result is similar in the literature [10,24] As mentioned earlier, the reason for this situation is due to the use of all data in the forward bias region for the Norde method, while the data in the linear region are used for the $I-V$ method.
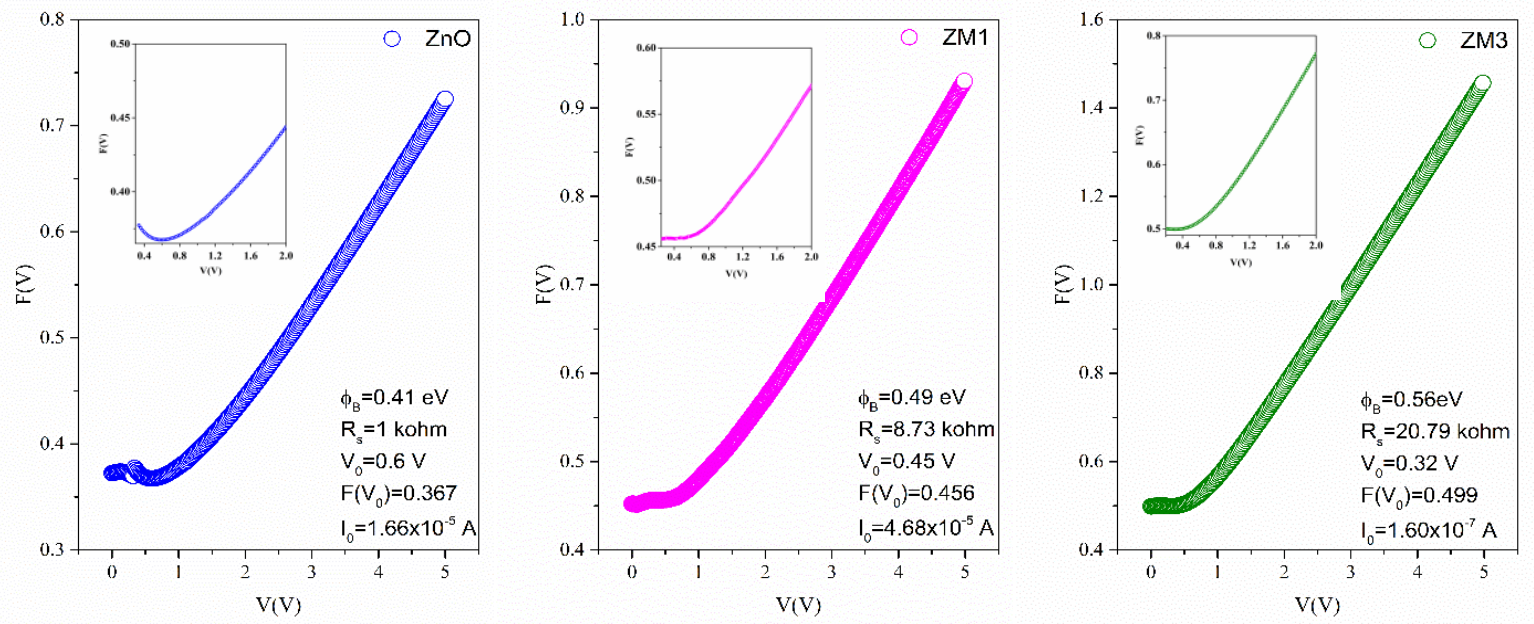

Figure 4. $F(V)-V$ plots of heterojunction diodes

In order to observe the photovoltaic behavior of the heterojunction diodes, $I-V$ measurements of the heterojunction diode were performed under dark and different light intensities. All these I-V characteristics are given in Figure 5. I-V measurements under illumination were performed using Solar simulator. Figure 5 shows that the heterojunction diodes are sensitive to the light and the reverse current increases with increasing illumination intensity. In the Table 2, experimentally determined open circuit voltages $\left(V_{o c}\right)$ and short circuit currents $\left(I_{s c}\right)$ values are given. Under illumination, the reverse current of the heterojunction diode is higher than the dark current. This result shows that the heterojunction diodes in this study exhibit photovoltaic behavior as a result of the photovoltaic effect, which is defined 
as the creation of a voltage and current of p-n heterojunctions when exposed to light intensities. Table 2 shows $I_{\text {photo }} / I_{\text {photo }}$ values under $-2 \mathrm{~V}$. According to the values in Table $2, \mathrm{n}-\mathrm{ZnO} / \mathrm{p}-\mathrm{Si}$ is the most sensitive to light among the diodes. The rectifier ratio $(R R)$ value given in Figure 6 is defined as the ratio of a certain forward bias current to a certain reverse bias current. The $R R$ value is associated with lighting illumination [25]. When these values are examined, it is seen that the most sensitive structure to illumination is $\mathrm{n}-\mathrm{ZnO} / \mathrm{p}-\mathrm{Si}$.

Table 2. Photovoltaic parameters of heterojunction diodes

\begin{tabular}{|c|c|c|c|}
\hline Sample & $\boldsymbol{V}_{\boldsymbol{o c}}(\mathbf{m V})$ & $\boldsymbol{I}_{\boldsymbol{s c}}(\mathbf{n A})$ & $\begin{array}{c}\boldsymbol{I}_{\text {photo }} / \boldsymbol{I}_{\text {photo }}(\mathbf{- 2 V}) \\
\left(\mathbf{1 0 0} \mathbf{m W} / \mathbf{c m}^{2}\right)\end{array}$ \\
\hline ZnO & 250 & 190 & 322 \\
\hline ZM1 & 240 & 5.97 & 75 \\
\hline ZM3 & 200 & 19.5 & 62 \\
\hline
\end{tabular}
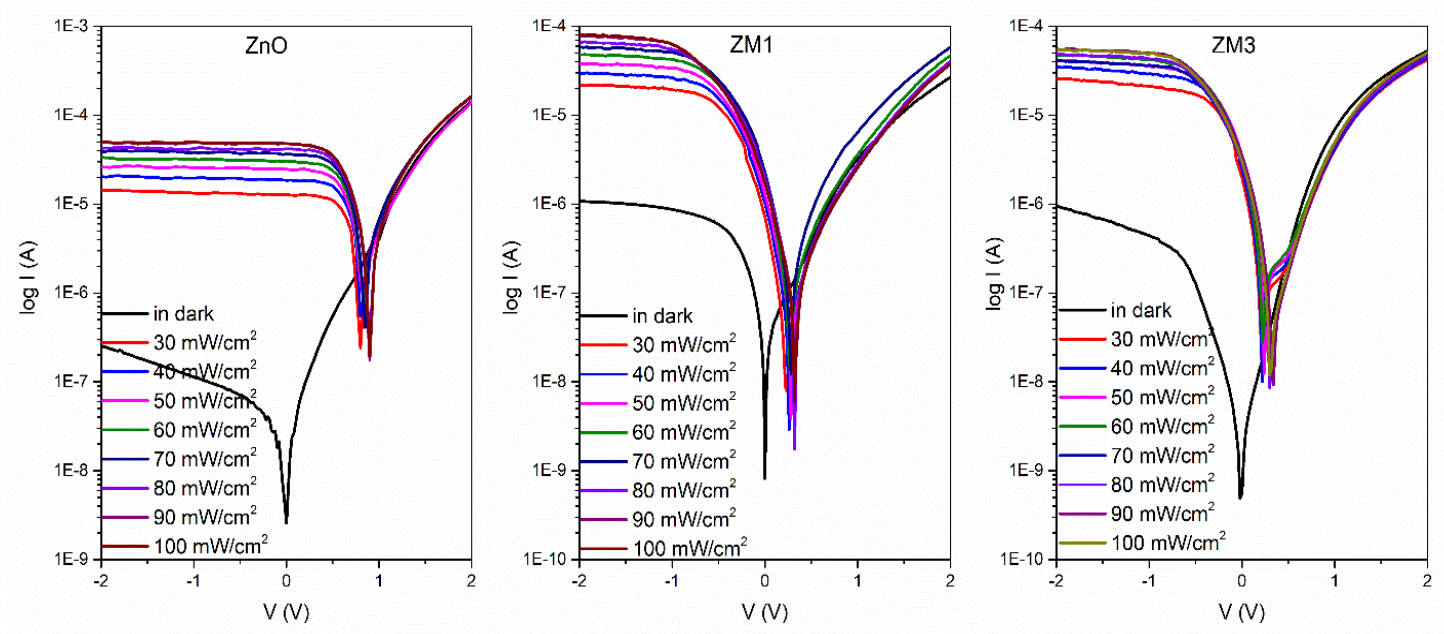

Figure 5. Current-voltage characteristics of the heterojunction diodes under dark and illumination conditions

In Figure 7, photocurrent-time plots are given. As shown in Figure 7, after switching the light source form on to off, the photocurrent values change over time. All of the heterojunction diodes exhibit photoconductivity. After the light is applied on the heterojunction diode, the photocurrent shows a sudden increase and after a while the photocurrent shows a plateau value. This situation is dependent on the difference between the electron affinity of the semiconductor material on the substrate and the substrate [23]. After the light source is turned off, the current returns to its first situation. 


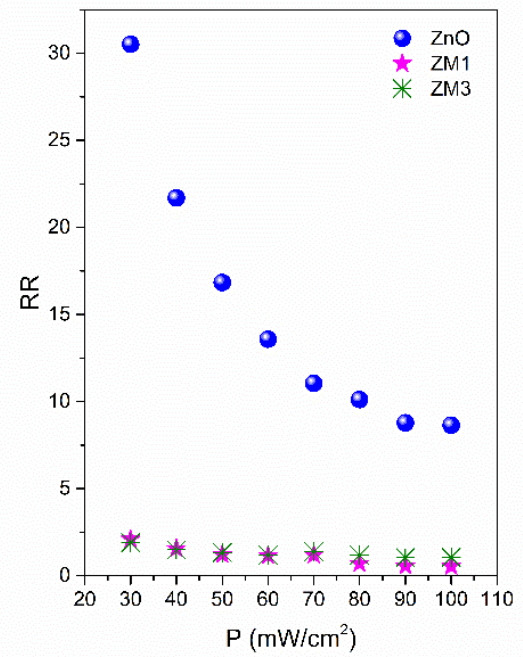

Figure 6. Plots of rectification ratio values vs. illumination intensity
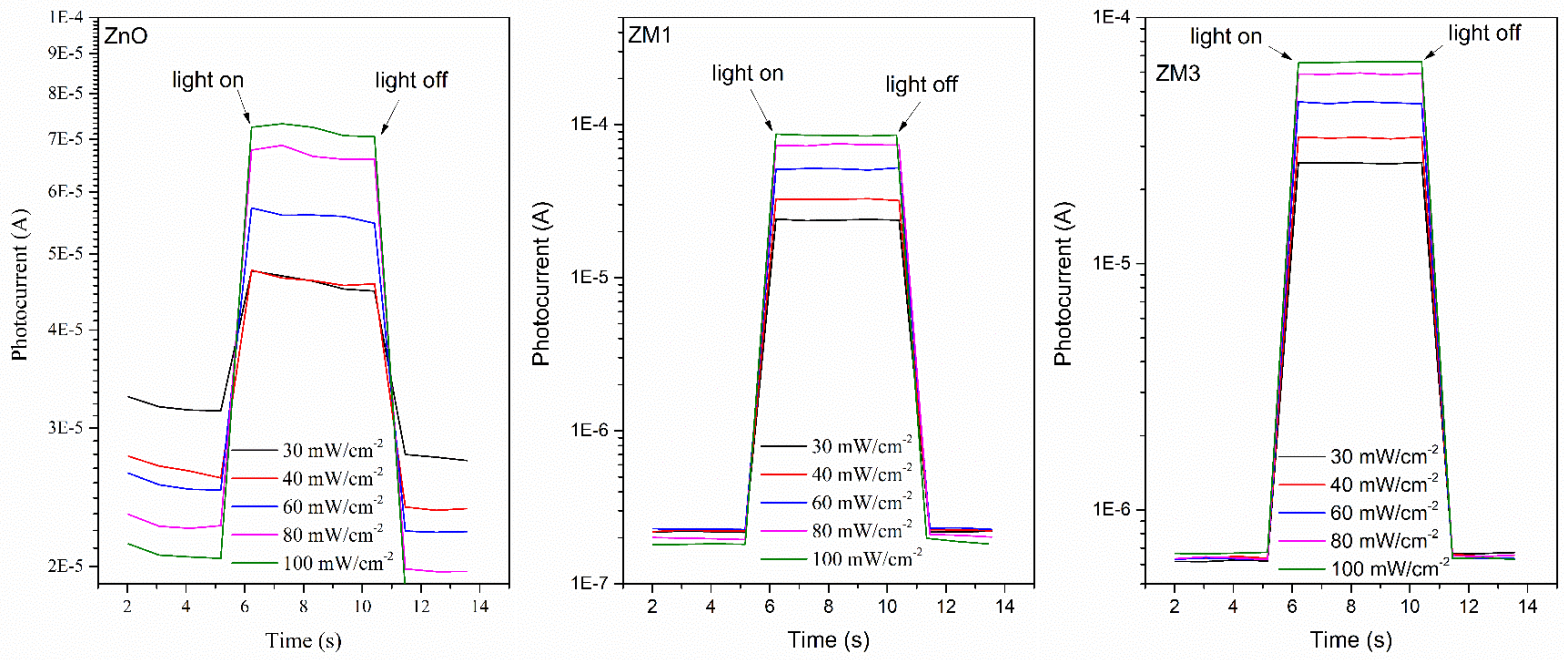

Figure 7. Time dependent photocurrent response of the heterojunction diodes under illumination.

Figure 8 shows the $C-V$ and $C^{-2}-V$ plots of the heterojunction diodes. The capacitance value changes as the width of the depletion region varies depending on the applied voltage. The relation between capacitance and voltage in heterojunction structures is defined by Equation 12 [19]:

$$
\frac{1}{C^{2}}=\frac{2\left(V_{b i}+V\right)}{A^{2} \varepsilon_{1} q N_{a}}
$$

where $V_{b i}$ is the built-in potential, $\varepsilon_{1}$ is the dielectric constant of $\mathrm{p}-\mathrm{Si}$ and $N_{a}$ is the acceptor concentration of $\mathrm{p}$-Si. The $V_{b i}$ values for the heterojunction diodes were determined from Figure 8 and these given in Table 3. The barrier height of the heterojunction diodes was also calculated using the following relation [19]: 


$$
\phi_{b(C-V)}=C_{2} V_{b i}+\frac{k T}{q} \ln \left(\frac{N_{v}}{N_{a}}\right)
$$

where $N_{v}$ is the density of states in the valance band of p-Si $\left(N_{v}=1.82 \times 10^{19} \mathrm{~cm}^{-3}\right), C_{2}$ is a parameter inverse of the ideality factor $\left(C_{2}=1 / n\right)$. The $\phi_{b}$ values of the heterojunction diodes were calculated using the $V_{b i}$ values determined using the $C^{-2}-V$ plots (Figure 8). These values are given in Table 3. The $\phi_{b}$ values obtained from $I-V$ measurement higher than the $\phi_{b}$ values obtained from $C-V$ measurements. This difference may be due to the fact that the interface layer thickness is non-uniform [26-28].

Table 3. Heterojunction diode parameters obtained from $C-V$ plots of the heterojunction diodes

\begin{tabular}{|c|c|c|}
\hline Sample & $\boldsymbol{V}_{\boldsymbol{b i}}(\mathbf{V})$ & $\boldsymbol{\phi}_{\boldsymbol{b}}(\boldsymbol{e} \boldsymbol{V})$ \\
\hline $\mathbf{Z n O}$ & 1.62 & 0.33 \\
\hline $\mathbf{Z M 1}$ & 2.52 & 0.42 \\
\hline $\mathbf{Z M 3}$ & 2.66 & 0.45 \\
\hline
\end{tabular}

Figure 8. Capacitance-voltage characteristics of the heterojunction diodes
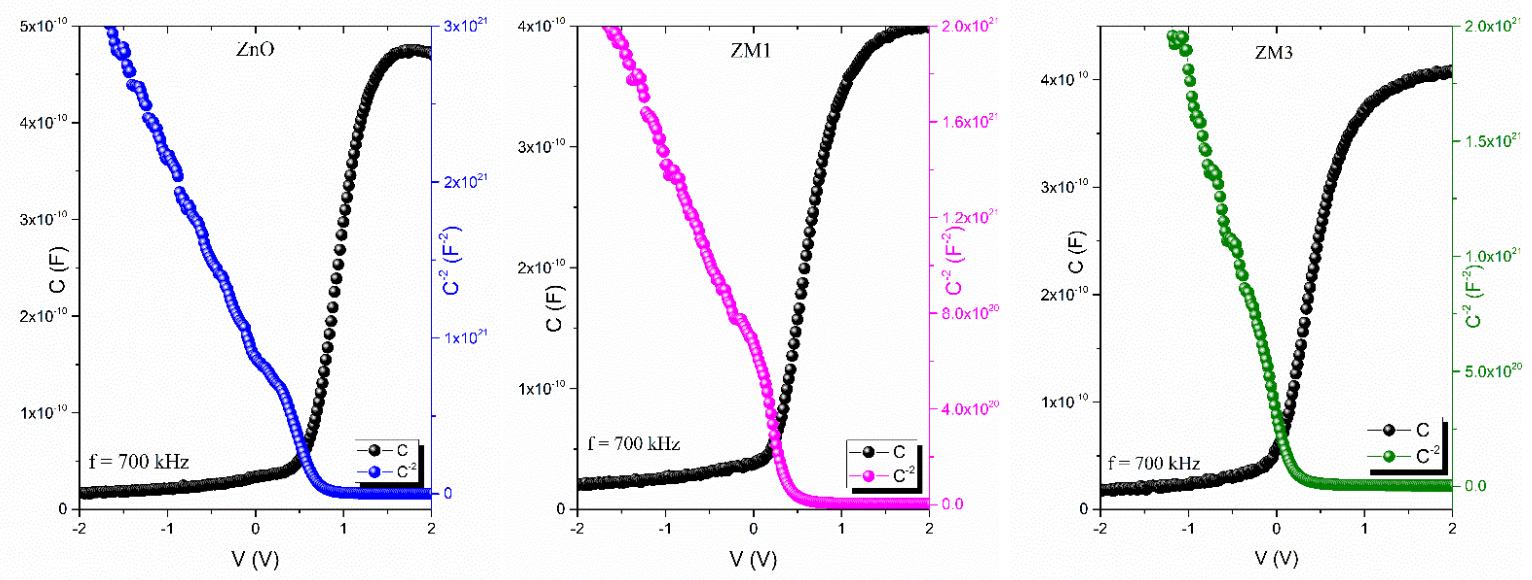

\section{CONCLUSIONS}

$\mathrm{ZnO}$ films were deposited in different $\mathrm{Mn}$ dopant ratio. Firstly, morphological characteristics of these films were studied. FESEM images of the films showed that an increase in particle size and increased aggregation on the surface depending increasing $\mathrm{Mn}$ dopant. Then, $\mathrm{n}-\mathrm{ZnO}: \mathrm{Mn} / \mathrm{p}-\mathrm{Si}$ heterojunction diodes were fabricated and the device performances were investigated. Diode parameters of the heterojunction diodes were calculated using $I-V$ plots. The results obtained from the $I-V$ characteristics showed that the rectifying properties of the $\mathrm{n}-\mathrm{ZnO} / \mathrm{p}-\mathrm{Si}$ heterojunction diode could be improved by the Mn dopant. Norde and Cheung methods were used to compare these parameters. In three methods, it was found that the calculated barrier height values increased with increasing Mn dopant. In addition, it was determined that the heterojunction diodes are sensitive to the light. The findings of this study showed that the heterojunction diodes fabricated using $\mathrm{Mn}$-doped $\mathrm{ZnO}$ film are candidates for use in semiconductor device applications.

\section{ACKNOWLEDGMENTS}

I would like to thank Prof. Dr. Yasemin Caglar for the FESEM and Electrical measurements. 


\section{REFERENCES}

[1] Hao YM, Lou S Y, Zhou SM, R. Yuan J, Zhu GY, Li N. Structural. optical. and magnetic studies of manganese-doped zinc oxide hierarchical microspheres by self-assembly of nanoparticles. Nanoscale Res. Lett. 2012; 7: 1-9.

[2] Sivalingam D, Gopalakrishnan JB, and Rayappan JBB. Structural, morphological, electrical and vapour sensing properties of $\mathrm{Mn}$ doped nanostructured $\mathrm{ZnO}$ thin films. Sensors Actuators, B Chem. 2012; 166-167: 624-631.

[3] Gayen RN, Paul R. Nanocrystalline Zn1-XMnxO thin film based transparent Schottky diodes. Thin Solid Films. 2016; 605: 248-256.

[4] Hammad TM, Griesing S, Wotocek M, Kuhn S, Hempelmann R, Hartmann U, Salem JK. Optical and magnetic properties of Fe-doped $\mathrm{ZnO}$ nanoparticles prepared by the sol-gel method. Int. J. Nanoparticles. 2013; 6: 324.

[5] Farag AAM, Cavas M, Yakuphanoglu F, Amanullah FM. Photoluminescence and optical properties of nanostructure $\mathrm{Ni}$ doped $\mathrm{ZnO}$ thin films prepared by sol-gel spin coating technique. J. Alloys Compd. 2011; vol. 509: 7900-7908.

[6] Abdel-Galil A, Balboul MR, Sharaf A. Synthesis and characterization of Mn-doped ZnO diluted magnetic semiconductors. Phys. B Condens. Matter. 2015; 477: 20-28.

[7] Dhara A, Sain S, Das S, Pradhan SK. Microstructure, optical, dielectric and electrical characterizations of $\mathrm{Mn}$ doped $\mathrm{ZnO}$ nanocrystals synthesized by mechanical alloying. Ceram. Int. 2018; 44: 7110-7121.

[8] Ahmed SA. Structural, optical, and magnetic properties of Mn-doped $\mathrm{ZnO}$ samples. Results in Physics. 2017; 7: 604-610.

[9] Alkhtaby LA, Husain S, Khan W, Naaqvi SAH. Structural and Optical Properties of Mn Doped ZnO Nanoparticles. Asian Journal of Chemistry. 2011; vol. 23: 5605-5607.

[10] Taşçioğlu I, Farooq WA, Turan R, Altindal Ş, Yakuphanoglu F. Charge transport mechanisms and density of interface traps in MnZnO/p-Si diodes. J. Alloys Compd. 2014; 590:157-161.

[11] Caglar Y, Gorgun K, Aksoy S. Effect of deposition parameters on the structural properties of ZnO nanopowders prepared by microwave-assisted hydrothermal synthesis. Spectrochim. Acta - Part A Mol. Biomol. Spectrosc. 2015; 138: 617-622.

[12] Aksoy S, Caglar Y. Effect of ambient temperature on electrical properties of nanostructure $\mathrm{n}-\mathrm{ZnO}$ / p-Si heterojunction diode. Superlatt. Microstruc. 2012; 51: 613-625.

[13] Amoupour E, Ghodsi FE, Andarva H, Ziabari AA, Preparation and investigation of optical, structural, and morphological properties of nanostructured ZnO:Mn thin films. Pramana. 2013; 81: $331-341$.

[14] Hu D, Liu X, Deng S, Liu Y, Feng Z, Han B, Wang Y, Wang Y. Structural and optical properties of Mn-doped $\mathrm{ZnO}$ nanocrystalline thin films with the different dopant concentrations. Phys. E LowDimensional Syst. Nanostructures. 2014; 61:14-22. 
[15] Sharma V, Dixit M, Satsangi VR, Dass S, Pal S, Shrivastav R. Photoelectrochemical splitting of water with nanocrystalline $\mathrm{Zn1}-\mathrm{xMnxO}$ thin films: First-principle DFT computations supporting the systematic experimental endeavor. Int. J. Hydrogen Energy. 2014; 39: 3637-3648.

[16] Rana VS, Rajput JK, Pathak TK, Purohit LP. Cu sputtered Cu/ZnO Schottky diodes on fluorine doped tin oxide substrate for optoelectronic applications. Thin Solid Films. 2019; 679:79-85.

[17] Yakuphanoglu F. Electrical characterization and device characterization of $\mathrm{ZnO}$ microring shaped films by sol-gel method. J. Alloys Compd. 2010; 507; 184-189.

[18] Sahu VK, Misra P, Ajimsha RS, Das AK, Singh B. Effect of growth temperature on diode parameters of $\mathrm{n}-\mathrm{ZnO} / \mathrm{p}-\mathrm{Si}$ heterojuction diodes grown by atomic layerde position. Mat. Sci. Semicon. Proc. 2016; 54:1-5.

[19] Sze SM. Physics of Semiconductor Devices, 2nd ed. Newyork, USA: Wiley, 1981.

[20] Cultrera A, Boarino L, Amato G, Lamberti C. Band-gap states in unfilled mesoporous nc-TiO 2 : measurement protocol for electrical characterization. J. Phys. D. Appl. Phys. 2014; 47: 15102.

[21] Cheung SK, Cheung NW. Extraction of Schottky diode parameters from forward current-voltage characteristics. Appl. Phys. Lett. 1986; 49: 85-87.

[22] Gupta RK, Ghosh K, Kahol PK. Fabrication and characterization of NiO/ZnO p-n junctions by pulsed laser deposition. Phys. E Low-dimensional Syst. Nanostructures. 2009; 41: 617-620.

[23] Norde H. A modified forward I- V plot for Schottky diodes with high series resistance. J. Appl. Phys. 1979; 50: 5052.

[24] Karabulut A. Barrier height modification in $\mathrm{Au} / \mathrm{Ti} / \mathrm{n}-\mathrm{GaAs}$ devices with a $\mathrm{HfO} 2$ interfacial layer formed by atomic layer deposition. Bull. Mater. Sci. 2019; 42:5: 1-11.

[25] Gorgun K, Caglar Y, Yakuphanoglu F. Synthesis and Photodiode Characterization of Novel Twisted Carbazole Derivatives with 1 , 3 , 5-Benzene Core. Silicon. 2018; 10: 693-702.

[26] Caglar Y, Caglar M, Ilican S, Yakuphanoglu F. Determination of the electronic parameters of nanostructure SnO2/p-Si diode. Microelectron. Eng. 2009; 86:2072-2077.

[27] Song YP, Van Meirhaeghe RL, Laflère WH, Cardon F. On the Difference in Apparent Barrier Height as Obtained from Capacitance-voltage and Current-voltage- temperature Measurements on Al/p-InP Schottky Barrier. Solid. State. Electron. 1986; 29, 633-638.

[28] Yakuphanoglu F, Şenkal BF. Electronic and Thermoelectric Properties of Polyaniline Organic Semiconductor and Electrical Characterization of Al/PANI MIS Diode. Phys. Chem. C. 2007; 111: 1846. 